\title{
Aortic valve-sparing reimplantation for dilatation of the ascending aorta and aortic regurgitation late after repair of congenital heart disease
}

Masamichi Ono, MD, ${ }^{a}$ Heidi Goerler, MD, ${ }^{a}$ Klaus Kallenbach, MD, ${ }^{a}$ Dietmar Boethig, MD, ${ }^{\mathrm{b}}$ Mechthild Westhoff-Bleck, MD, ${ }^{\mathrm{c}}$ and Thomas Breymann, MD ${ }^{\mathrm{a}}$

Objective: Aortic regurgitation resulting from progressive dilatation of the aortic root late after surgical correction of congenital heart disease is now widely recognized. We reviewed our experience with aortic valve-sparing operations to access the effectiveness of this approach.

Methods: Three patients, aged 28, 31, and 32 years, had progressive dilatation of the ascending aorta and aortic regurgitation 25,27 , and 28 years, respectively, after surgical repair of complex congenital heart disease. At the time of reoperation, the maximum diameter of the aortic root ranged between 50 and $55 \mathrm{~mm}$.

Results: All 3 patients survived the operation and were in New York Heart Association functional class II or less at a maximum of 9 years' follow-up. The most recent echocardiogram demonstrated mild or less aortic insufficiency with favorable systemic ventricular function.

Conclusions: Aortic valve-sparing reimplantation is an effective treatment for aortic root dilatation and aortic regurgitation after corrective repair of complex congenital heart disease. This procedure leads to correction of aortic regurgitation, favorable durability of the native aortic valve, and excellent hemodynamics, avoiding a prosthetic valve and anticoagulation.

From the Divisions of Thoracic and Cardiovascular Surgery, ${ }^{\text {a }}$ Pediatric Cardiology, Intensive Care Medicine, ${ }^{\mathrm{b}}$ and Cardiology, Hannover Medical School, Hannover, Germany.

Received for publication Oct 20, 2006; accepted for publication Oct 30, 2006.

Address for reprints: Masamichi Ono, MD, Division of Thoracic and Cardiovascular Surgery, Hannover Medical School, CarlNeuberg-Str 1, 30625 Hannover, Germany (E-mail: Ono.Masamichi@mh-hannover. de).

J Thorac Cardiovasc Surg 2007;133:876-9

$0022-5223 / \$ 32.00$

Copyright (๑) 2007 by The American Association for Thoracic Surgery

doi:10.1016/j.jtcvs.2006.10.055
$\mathrm{A}$ long with the increasing number of adult patients who have had surgical repair of complex congenital heart disease (CHD), several reports describe the incidence of late-developing aortic root dilatation and late progression of aortic regurgitation (AR), even after an uncomplicated repair. ${ }^{1-4}$ If surgical repair is required, composite graft replacement has been performed.

The aortic valve reimplantation technique, first described by David and Feindel, ${ }^{5}$ leads to excellent clinical outcomes in patients with AR and aneurysms of the ascending aorta. Avoidance of the need for anticoagulation and favorable long-term results should encourage the extension of indications for this technique.

In this study, we present 3 cases of progressive aortic root dilation and AR late after surgical repair of complex CHD, which was successfully managed by valvesparing aortic root reimplantation.

\section{Patients and Methods}

Between July 1997 and June 2006, 3 patients, aged 28, 31, and 32 years, were referred to our institution with progressive aortic root dilatation and AR after corrective repair of CHD. Two patients received corrective repair of tetralogy of Fallot (TOF) at 4 and 6 years of age, and the other patient underwent a Mustard operation for transposition of the great arteries at the age of 1 year. Demographic and diagnostic features are summarized in Table 1. 

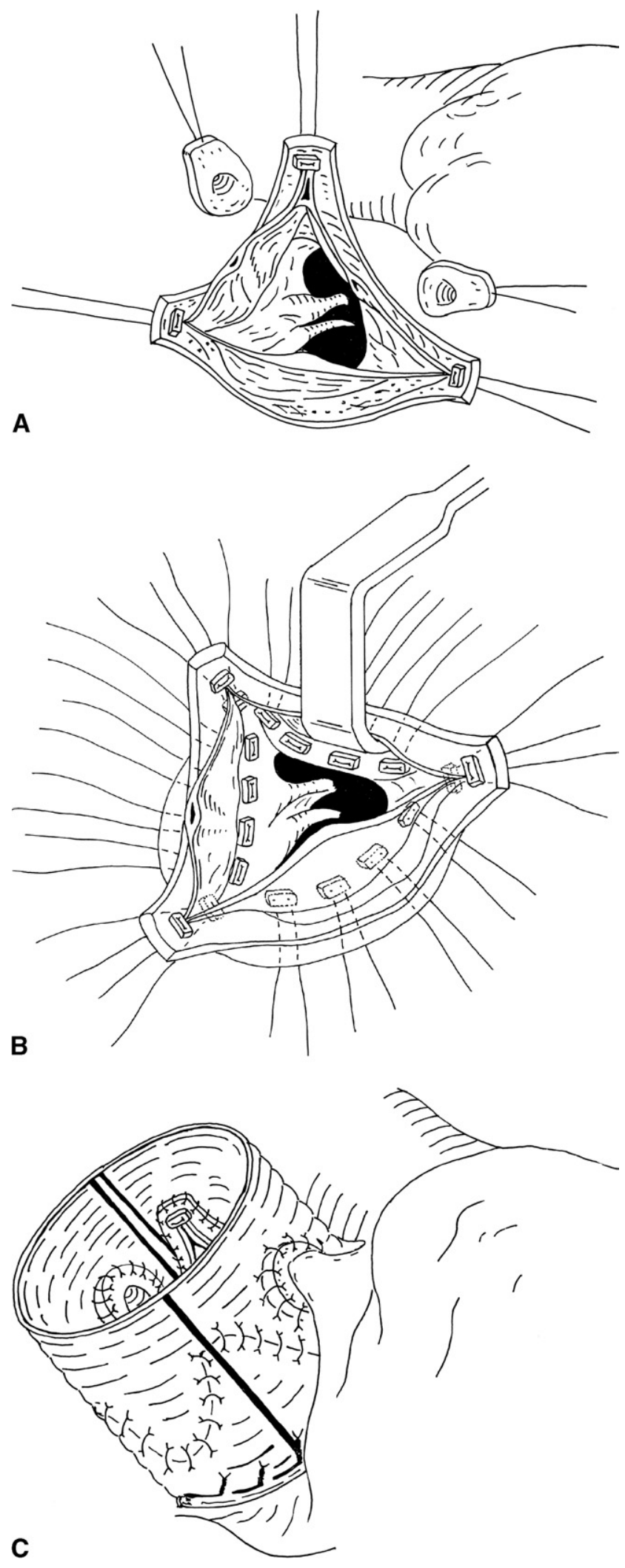

Abbreviations and Acronyms

$\mathrm{AR}=$ aortic regurgitation

$\mathrm{CHD}=$ congenital heart disease

$\mathrm{TOF}=$ tetralogy of Fallot

\section{Surgical Technique}

Reoperation was performed at intervals of 25, 27, and 28 years after the primary repair. Data at the valve-sparing operations are shown in Table 2. Because the dilated ascending aorta was lying just below the sternum, cardiopulmonary bypass was initially established by cannulation of the femoral artery and vein. Then, median sternotomy was carefully done with an oscillating saw. The ascending aorta, right atrium, superior vena cava, inferior vena cava, and right upper pulmonary vein were fully dissected out. Another venous cannula was inserted to the superior vena cava in the patients with normal systemic venous return or to the hepatic vein through the right atrium in the patient with hemiazygos continuation. A vent tube was placed to the systemic ventricle through the right upper pulmonary vein in patients with TOF or through the functional left atrium (anatomic right atrium) in the patient after the Mustard operation. Deep to moderate hypothermia $\left(20^{\circ} \mathrm{C}-27^{\circ} \mathrm{C}\right)$ was initiated to control collateral flow to the systemic ventricle. When the aortic crossclamp was placed and cardioplegic cardiac arrest was instituted, the proximal portion of the ascending aorta was transected at the sinotubular junction. After mobilization of the aortic root, coronary buttons were excised and aortic sinuses up to a remnant of 2 to $3 \mathrm{~mm}$ were resected (Figure 1, A). A proximal anastomosis was performed with 12 to 15 threads of 3-0 coated polyester fiber (Ethibond; Ehicon, Inc, Somerville, NJ) used as horizontal mattress sutures placed through the annulus underneath the valve (Figure 1, B). The aortic cuff, including the commissures, was reimplanted into the Dacron prosthesis (28 or $30 \mathrm{~mm}$ ) with three 4-0 polypropylene sutures (Prolene; Ethicon Inc) using a running technique (Figure 1, C). Integration of the coronary buttons into the prosthesis completed the aortic root reconstruction. Finally, the distal end of the prosthesis

Figure 1. A, After mobilization of the aortic root, coronary buttons were excised and aortic sinuses up to a remnant of 2 to $3 \mathrm{~mm}$ were resected. B, A proximal anastomosis was performed with 12 to 15 threads of 3-0 coated polyester fiber used as horizontal mattress sutures placed through the annulus underneath the valve. C, The aortic cuff, including the commissures, was reimplanted into the Dacron prosthesis $(28$ or $30 \mathrm{~mm})$ with three 4-0 polypropylene sutures using a running technique. The coronary buttons were also reimplanted into the prosthesis. 
TABLE 1. Summary of data before valve-sparing operation

\begin{tabular}{|c|c|c|c|c|c|c|c|}
\hline Patient no. & $\begin{array}{c}\text { Age at operation } \\
(y) / \text { sex }\end{array}$ & Weight $(\mathrm{kg})$ & Primary diagnosis & Radical operation & $\begin{array}{l}\text { Age at radical } \\
\text { operation (y) }\end{array}$ & $\begin{array}{l}\text { Diameter of } \\
\text { ascending } \\
\text { aorta }(\mathrm{mm})\end{array}$ & Degree of AR \\
\hline 2 & 28/M & 80 & d-TGA CoA & $\begin{array}{l}\text { Mustard operation; } \\
\text { CoA repair }\end{array}$ & 1 & 50 & Moderate \\
\hline
\end{tabular}

TOF, Tetralogy of Fallot; Rt, right; $d$-TGA, d-transposition of the great arteries; SCA, subclavian artery; CoA, coarctation of the aorta.

TABLE 2. Summary of data at valve-sparing operation

\begin{tabular}{|c|c|c|c|c|c|c|}
\hline Patient no. & $\begin{array}{l}\text { Arterial/venous } \\
\text { cannulation }\end{array}$ & $\begin{array}{c}\text { Diameter of vascular } \\
\text { graft }(\mathbf{m m})\end{array}$ & CPB time (min) & $\begin{array}{c}\text { Crossclamp } \\
\text { time (mm) }\end{array}$ & $\begin{array}{l}\text { Lowest rectal } \\
\text { temperature }\left({ }^{\circ}\right)\end{array}$ & $\begin{array}{l}\text { Concomitant } \\
\text { procedures }\end{array}$ \\
\hline 1 & FA/FV, HV & 28 & 199 & 120 & 22 & None \\
\hline 2 & FA/FV, SVC & 28 & 356 & 123 & 20 & None \\
\hline 3 & FA/FV, SVC & 30 & 223 & 120 & 27 & Re-RVOTR \\
\hline
\end{tabular}

FA, Femoral artery; FV, femoral vein; $H V$, hepatic vein; SVC, superior vena cava; RVOTR, right ventricular outflow tract reconstruction.

TABLE 3. Summary of data after valve-sparing operation

\begin{tabular}{ccccccccc}
\hline Patient no. & AR after redo & ICU stay & Hospital stay & Follow-up period (mo) & AR at last visit & NYHA class & Reop & Thromboembolism \\
\hline 1 & 0 & 1 & 19 & 108 & $0-1$ & II & None & None \\
2 & 0 & 1 & 6 & 10 & 0 & None & None \\
3 & 0 & 1 & 6 & 6 & 0 & I & None & None \\
\hline
\end{tabular}

$A R$, Aortic regurgitation; ICU, intensive care unit; NYHA, New York Heart Association; Reop, reoperation.

was anastomosed with the distal ascending aorta using running sutures.

In patient 3 , in whom pulmonary regurgitation developed after initial corrective surgery for TOF, a repeat right ventricular outflow reconstruction with a $22-\mathrm{mm}$ bovine jugular vein (Contegra; Medtronic, Inc, Minneapolis, Minn) was performed concomitantly.

\section{Results}

All patients survived the procedure. Their postoperative course was uneventful except in patient 1 , who had transient tachyarrhythmia controlled by medical treatment. Intensive care unit stay was 1 day for all 3 patients, and hospital stay was 6 to 19 days. Echocardiography performed during the hospital stay showed minimal AR in all patients. Follow-up periods were 108, 10, and 6 months, respectively. All patients were alive and in New York Heart Association functional class II or less. In the 2 patients who were recently operated on, the aortic valve was completely competent. The other patient had mild AR at the most recent communication, but the patient remained in good condition. In all patients, there was neither thromboembolic complication nor need for reoperation. Postoperative data are summarized in Table 3.

\section{Discussion}

In this report, we presented our experience with the aortic valve-sparing reimplantation technique, which was applied for progressive aortic dilatation and AR in adult patients late after corrective surgery for CHD.

The occurrence of AR after complete repair in patients with TOF is relatively uncommon but widely recognized. ${ }^{1,2}$ An anomaly of the aortic valve, a bulboventricular ventricular septal defect, infective endocarditis, or surgical manipulation during the repair can aggravate the AR. In addition, an increasing number of reports, involving a growing cohort of patients with long-term follow up, describe the incidence of late-developing AR in association with aortic root dilation even after an uncomplicated repair. ${ }^{3}$ In these patients, aortic valve leaflets are intact, and aortic root dilatation may be the cause of AR. Structural abnormality of the aortic wall, which was proved histologically in patients with TOF, truncus arteriosus, and transposition of the great arteries, ${ }^{4}$ may explain this phenomenon. All of the patients of our study had intact aortic valve leaflets and associated dilatation of the aortic annulus and ascending aorta, which was thought to be a good indication for the aortic valve-sparing operation, rather than aortic valve replacement or composite graft implantation. 
Inasmuch as valve-sparing operations were originally performed for adult patients with AR and aneurysm of the ascending aorta, ${ }^{5,6}$ indications for this technique have been extended to Marfan syndrome, ${ }^{7}$ acute aortic dissection type $\mathrm{A},{ }^{8}$ and dilatation of pulmonary autografts after the Ross operation. ${ }^{9}$ Freedom from anticoagulation, favorable durability of the native aortic valve, and excellent hemodynamics encourage further use of this repair. ${ }^{10}$

As for the technical aspect for reoperation in patients with cyanotic CHD, they showed a considerable amount of collateral flow even after corrective repair, which must be controlled by moderate to deep hypothermia and vent suction. Initial establishment of cardiopulmonary bypass through femoral access before thoracotomy, cooling phase, and rewarming phase needed relatively long cardiopulmonary bypass time, but reoperation was performed safely and bleeding was controlled. As David and associates ${ }^{11}$ demonstrated in their experience with aortic root replacement in patients with previous heart surgery, our initial results may lead to comparable results to those for patients who have valve-sparing operation for the first time. Anatomic variation of the great arteries did not cause any difference in our 3 patients.

In conclusion, although a larger number of patients and extended follow-up studies are required for final judgment, valve-sparing reimplantation showed excellent results for management of aortic root dilatation and AR in adult patients after complex CHD repair.

\section{References}

1. Dodds GA 3rd, Warnes CA, Danielson GK. Aortic valve replacement after repair of pulmonary atresia and ventricular septal defect or tetralogy of Fallot. J Thorac Cardiovasc Surg. 1997;113:736-41.

2. Ishizaka T, Ichikawa H, Sawa Y, Fukushima N, Kagisaki K, Kondo H, et al. Prevalence and optimal management strategy for aortic regurgitation in tetralogy of Fallot. Eur J Cardiothorac Surg. 2004;26:1080-6.

3. Niwa K, Siu SC, Gray SM, Webb GD, Gatzoulis MA. Progressive aortic root dilatation in adults late after repair of tetralogy of Fallot. Circulation. 2002;106:1374-8.

4. Niwa K, Perloff JK, Bhuta SM, Laks H, Drinkwater DC, Child JS, et al. Structural abnormalities of great arterial walls in congenital heart disease. Light and electron microscopic analyses. Circulation. 2001; 103:393-400.

5. David TE, Feindel CM. An aortic valve-sparing operation for patients with aortic incompetence and aneurysm of the ascending aorta. J Thorac Cardiovasc Surg. 1992;103:617-22.

6. Harringer W, Pethig K, Hagl C, Meyer GP, Haverich A. Ascending aortic replacement with aortic valve reimplantation. Circulation. 1999; 100(suppl II):II24-8.

7. Karck M, Kallenbach K, Hagl C, Rhein C, Leyh R, Haverich A. Aortic root surgery in Marfan syndrome: comparison of aortic valve-sparing reimplantation versus composite grafting. J Thorac Cardiovasc Surg. 2004;127:391-8.

8. Kallenbach K, Oelze T, Salcher R, Hagl C, Karck M, Leyh R, et al. Evolving strategies for treatment of acute aortic dissection type A. Circulation. 2004;110(suppl II):II243-9.

9. Ishizaka T, Devaney EJ, Ramsburgh SR, Suzuki T, Ohye RG, Bove EL. Valve sparing aortic root replacement for dilatation of the pulmonary autograft and aortic regurgitation after the Ross procedure. Ann Thorac Surg. 2003;75:1518-22.

10. Kallenbach K, Karck M, Pak D, Salcher R, Khaladj, N, Leyh R, et al. Decade of aortic valve sparing reimplantation. Are we pushing the limits too far? Circulation. 2005;112(suppl I):I253-9.

11. David TE, Feindel CM, Ivanov J, Armstrong S. Aortic root replacement in patients with previous heart surgery. J Card Surg. 2004;19: 325-8. 